(c) 2019. This manuscript version is made available under the CC-BY-NC-ND 4.0 license http://creativecommons.org/licenses/by-ncnd/4.0/

Post-print version: “Casado-Barrasa, R., Lastra-González, P., Indacoechea-Vega, I., \& Castro-Fresno, D. (2019). Assessment of carbon black modified binder in a sustainable asphalt concrete mixture. Construction and Building Materials, 211, 363-370. doi:10.1016/j.conbuildmat.2019.03."

\title{
ASSESSMENT OF CARBON BLACK MODIFIED BINDER IN A SUSTAINABLE
} ASPHALT CONCRETE MIXTURE

Raquel Casado a , Pedro Lastra-González ${ }^{\mathrm{b}}$, Irune Indacoechea-Vega ${ }^{\mathrm{b}}$, Daniel Castro-Fresno ${ }^{\mathrm{b}, *}$

${ }^{a}$ ACCIONA Construction Innovation Technology Division. C/ Valportillo II n ${ }^{\circ}$ 8, 28108

Alcobendas, Madrid, Spain.

Raquel Casado

raquel.casado.barrasa@acciona.com

6

b GITECO Research Group, Universidad de Cantabria. E.T.S. Ingenieros de Caminos, Canales y Puertos de Santander, Av. de los Castros s/n, 39005 Santander, Spain

Pedro Lastra-González pedro.lastragonzalez@unican.es

Irune Indacoechea-Vega irune.indacoechea@unican.es

Daniel Castro-Fresno castrod@unican.es

$9 \quad *$ Corresponding author: Daniel Castro Fresno

10

11

12

13

14

15

16

17

18

19

20

21

22

23

24

25

26

27

Tel.: +34942 2039 zx 43

Fax: +34 942201703

\section{Abstract}

Carbon black has been used as a modifier in conventional binders together with a relatively low percentage of SBS polymer. In addition, an Evotherm additive has been combined by the wet way with the aim of decreasing the manufacturing temperature of the asphalt mixtures. The impact of these two has been analysed with a DSR rheometer, showing an increase in stiffness. An Asphalt Concrete mixture was then designed using the experimental binder and the warm mix additive and compared with a reference mix, using a commercial polymer modified bitumen.

The final experimental mixture was manufactured $15^{\circ} \mathrm{C}$ cooler than usual, showing good mechanical performance despite the low percentage of natural aggregate, which was mostly composed of reclaimed asphalt and slag. Its stiffness and fatigue resistance were also investigated. Finally, the mixture was laid in an experimental road section under real conditions as proof of concept of the technology.

\section{Keywords}

Carbon black; Evotherm; Asphalt Concrete; Electric Arc Furnace Slag; Reclaimed Asphalt. 


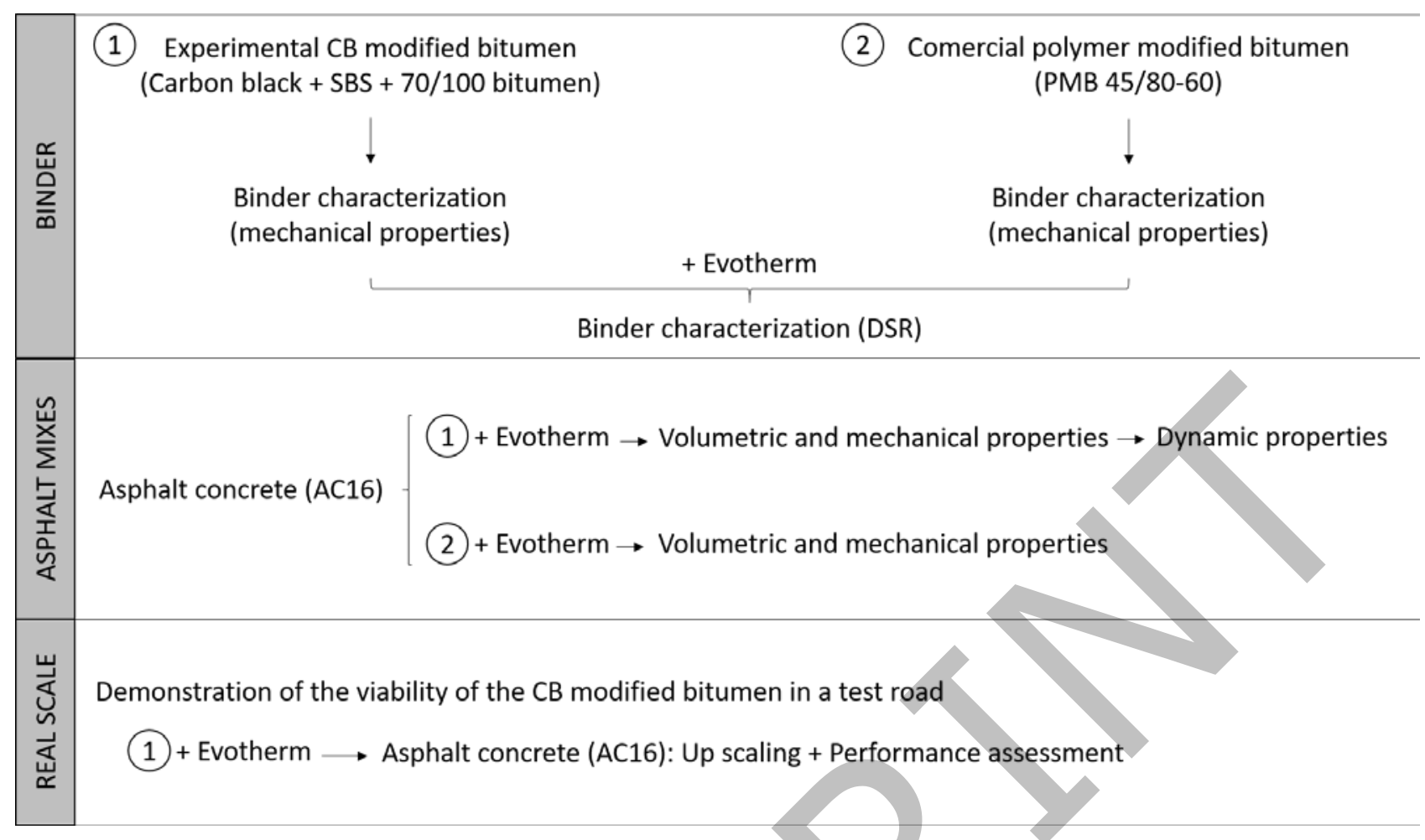

Highlights

- Carbon Black was used with SBS to modify a conventional binder

- Evotherm was added by wet way to decrease the manufacturing temperature

- An AC mixture was designed with a high percentage of EAF slag and RA

- The AC mixture was validated in a test section under real conditions

\section{INTRODUCTION}

The transport sector has recently been undergoing a slow transition towards the inclusion of more sustainable bituminous mixtures in the construction of road infrastructures. Many concepts and approaches are being introduced to achieve greener mixtures, such as the recycling of materials (e.g. by-products ${ }^{1}$ or waste ${ }^{2}$ ), the addition of new materials as additives to modify the characteristics of the mixtures ${ }^{3,4}$, or binder modification to improve some mechanical properties ${ }^{5}$. Inclusion of these products can be successful only after full investigation of their sources and properties, being generally feasible at low levels of incorporation, with continuous monitoring of the road's final performance. Slag from Electric Arc Furnaces (EAF) and Reclaimed Asphalt (RA) are among the most common materials used to replace natural aggregates. The former has great properties as coarse aggregate ${ }^{6-8}$,

44 the latter also enables the quantity of virgin binder to be reduced ${ }^{9}$, depending on the properties of the 45 RA and the method of incorporation ${ }^{10,11 .}$ 
Aside from aggregates, bitumen has a great influence on the environmental impact of the mixture, first because it is a finite material derived from petroleum, second because its properties are directly linked to the asphalt mix production temperature, which has exponential correlation with gas emissions ${ }^{12}$. There are three well-known techniques to decrease the manufacturing temperature: the use of waxes to modify the viscosity of the binder, the foaming process based on the addition of water, and the incorporation of chemical additives that improve the workability of the mixture. All these approaches fall under the category of Warm Mix Asphalt (WMA). Evotherm is one of the most commonly used additives in the United States, also introduced in Europe, to achieve WMA. It was first a water-based product, being developed as a free water additive, decreasing the manufacturing temperatures by around $40{ }^{\circ} \mathrm{C}$ in Hot Mix Asphalt (HMA) ${ }^{13}$. It has also been used in mixtures with modified binders, achieving good mechanical properties, although the reduction in the production temperature was slightly lower $\left(30^{\circ} \mathrm{C}\right){ }^{14}$.

The modification of bitumen is one of the most useful methods to improve the mechanical performance and to increase the lifespan of the mixtures. In a recent study, the Asphalt Institute demonstrated that the service life of HMA is extended between 3 and 6 years when a polymermodified bitumen is used ${ }^{15}$. Traditionally, polymers such as styrene-butadiene-styrene (SBS), styrene-butadiene rubber (SBR), rubber, or ethylene vinyl acetate (EVA) have been used to produce modified bitumens. The incorporation of these materials is generally aimed at increasing resistance to rutting and thermal cracking, and decreasing fatigue damage, stripping and temperature susceptibility ${ }^{16}$.

Recently, besides the use of polymers to produce modified bitumens, there is a trend to incorporate nanomaterials as additives to modify the binder, such as carbon derived materials; eg. carbon black (CB) or graphite. These materials can modify the internal structure of asphalt and improve its high temperature properties, increasing the resistance to plastic deformation and the elasticity, as well as affecting other properties such as the electrical conductivity ${ }^{17-20}$.

The production of asphalt mixtures can include one or more of the above-mentioned technologies, either to assess mixture performance or environmental impact. Some authors have reported the technical performance of the combined use of WMA with RA, EAF, or modified binders ${ }^{21-23}$, but there is still a lack of knowledge about the overall performance of these techniques.

In this study, a deep analysis of an AC mixture when a commercial polymer modified bitumen (PMB) and an experimental bitumen with CB have been used is presented. Attempting to normalise the use of waste in bituminous mixtures and improving their environmental impact (although this is not the 
core of the study), black slags of electric arc furnace and RA have been added as partially replacement of aggregates, aside from the use of Evotherm to reduce the manufacturing temperature. In both cases, when using $\mathrm{PMB}$ and $\mathrm{CB}$ as bituminous binder, the conditions of asphalt mix production, particle size distribution and percentage of bitumen were the same, so that only the impact of CB respect the most commonly used polymers have been assessed. This study has been carried out by ACCIONA Construction.

\section{MATERIALS AND METHODS}

\subsection{Experimental methodology}

Different blends with percentages of carbon black from 1.5\% to 9\% and $3 \%$ of SBS were prepared and characterised according to EN 14023. In addition, the optimum formulation of modified bitumen with CB and the commercial binder were assessed by Dynamic Shear Rheometer according to EN 14770 (with and without Evotherm).

An AC16 surface layer mixture was later designed in different phases to compare the impact on mixture performance of the bitumen types used.

The samples were prepared following the same procedure. Polymer-modified bitumen was heated to $165^{\circ} \mathrm{C}$, while natural aggregates and steel slags were heated to a higher temperature than normal, $200{ }^{\circ} \mathrm{C}$ for 8 hours, since percentages higher than $20 \%$ of RA were incorporated. RA was dried in a ventilated oven for 2 hours at $110{ }^{\circ} \mathrm{C}$ in order to avoid further ageing the binder in the reclaimed asphalt. Once the Evotherm was incorporated ( $0.4 \%$ by mass of the new binder), the bitumen temperature for the manufacturing of the mixture was reduced to $150{ }^{\circ} \mathrm{C}$ for both binders; this is the same range of temperatures than conventional 50/70 penetration grade binder.

The AC performance of each binder (commercial and experimental) was evaluated using the mechanical tests required by the Spanish standards: air void content (UNE EN 12697 - 8), water sensitivity (UNE EN 12697 - 12) and wheel tracking (UNE EN 12697 - 22). Dynamic tests were also conducted on the final mixture with the CB polymer-modified binder, such as stiffness (UNE EN 12697 - 26) and fatigue resistance (UNE EN 12697 - 24).

\subsection{Description of materials}

The properties of the materials used for the preparation of the AC mixtures in the investigation are shown below.

\section{Bitumen}


Two binders were used in the study. The polymer-modified bitumen (PMB 45/80 - 60) used as a reference was a commercial binder while the experimental carbon black-modified bitumen was produced in situ by ACCIONA. This experimental binder was produced by mixing 70/100 penetration grade bitumen, carbon black (CB) and styrene-butadiene-styrene (SBS). A laboratory modification plant provided with high shear mixing was used to achieve a homogenous dispersion of the individual carbon particles and SBS in bitumen (Figure 1). The CB and SBS materials were continuously loaded into the preheated bitumen unit at $175^{\circ} \mathrm{C}$. Once the full amount desired was added, the components were stirred and recirculated during 1 hour and 30 minutes at medium speed 300-500 rpm to avoid the polymer settle at the bottom of the tank. After the stirring process, all components were passed through a High Shear Mixer (HSM) mill at $200 \mathrm{~Hz}$ during 15-30 minutes. When the milling process was completed the carbon polymer modified bitumen produced was collected in different containers for laboratory characterization.

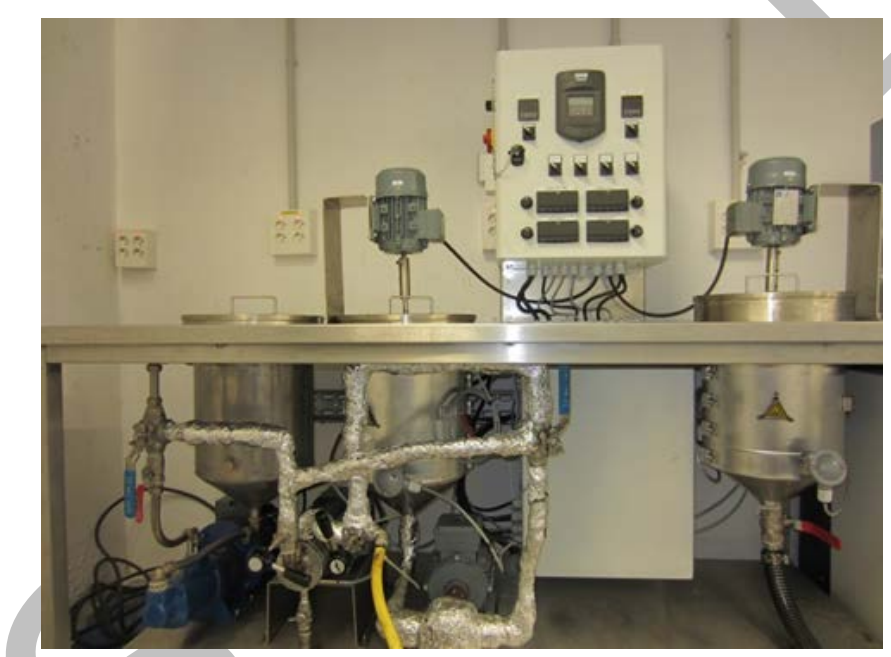

Figure 1. DISPERMAT mixing plant at laboratory level

Finally, an optimum formulation of $6 \%$ carbon black and 3\% of SBS was selected for the experimental binder, whose results are shown in Table 1 below. The acceptable values according to the Spanish specifications for polymer-modified bitumen are also included for comparison purposes.

\begin{tabular}{|c|c|c|c|}
\hline Property & Standard & CB bitumen & PMB 45/80 -60 \\
\hline Penetration@25C (0,1 mm) & EN 1426 & 45.3 & $45-80$ \\
\hline Softening point $\left({ }^{\circ} \mathrm{C}\right)$ & EN 1427 & 71.0 & $\geq 60$ \\
\hline Fraass breaking point $\left({ }^{\circ} \mathrm{C}\right)$ & EN 12593 & -12 & $\leq-12$ \\
\hline $\begin{array}{l}\text { Cohesion force ductility @ } 5^{\circ} \mathrm{C} \text {, } \\
50 \mathrm{~mm} / \mathrm{min}(\mathrm{J} / \mathrm{cm} 2)\end{array}$ & EN 13589 & 14.2 & $\geq 2$ \\
\hline Elastic recovery @ 25ㄷ C (\%) & EN 13398 & 91 & $\geq 50$ \\
\hline Dynamic viscosity @ 135² C (cP) & EN 13302 & 2283 & - \\
\hline Dynamic viscosity @ 150C (cP) & EN 13302 & 1150 & - \\
\hline
\end{tabular}




\begin{tabular}{|c|c|c|c|}
\hline Dynamic viscosity@185² (cP) & EN 13302 & 367 & - \\
\hline \multicolumn{4}{|c|}{ Storage stability at $180{ }^{\circ} \mathrm{C}$} \\
\hline Difference in softening point $\left({ }^{\circ} \mathrm{C}\right)$ & EN 1426 & 6 & $\leq 9$ \\
\hline Difference in penetration $(0.1 \mathrm{~mm})$ & EN 1427 & 1.6 & $\leq 5$ \\
\hline \multicolumn{4}{|c|}{ Determination of the resistance to hardening under influence of heat and air (RTFOT) } \\
\hline Change of mass (\%) & EN 12607-1 & 0.04 & $\leq 1.0$ \\
\hline Retained penetration (\%) & EN 1426 & 87 & $\geq 60$ \\
\hline Increase in softening point $\left({ }^{\circ} \mathrm{C}\right)$ & EN 1427 & 3.6 & $\leq 10$ \\
\hline
\end{tabular}

126 Properties of the CB-modified results are within the acceptable values for a commercial PMB 40/8012760.

\section{Aggregates}

129 Limestone was the only natural aggregate used in the research. It was added to complete the particle 130 size distribution for the fine fraction $(0-6 \mathrm{~mm})$. Steel slags from EAFs were obtained from a local 131 company in Cantabria, in the north of Spain. The company treated them before their supply, so they 132 comply with the leaching ${ }^{24}$ requirements and do not display expansiveness. They were used basically 133 as coarse aggregate. The main properties of these materials are shown in Table 2, along with the 134 minimum requirements that should be fulfilled according to the Spanish specification for the most 135 demanding traffic level.

\begin{tabular}{lcccc}
\hline \multicolumn{1}{c}{ Property } & Standard & Limestone & Steel slag & $\begin{array}{c}\text { Limits } \\
\text { (Spanish Standard) }\end{array}$ \\
\hline Specific weight $\left(\mathrm{g} / \mathrm{cm}^{3}\right)$ & EN 1097 -6 & 2.661 & 3.821 & - \\
Flakiness index & EN 933 - 3 & 10 & 2 & $<20$ \\
Los Angeles coefficient & EN 1097 - 2 & 19 & 18 & $\leq 20$ \\
Sand equivalent (\%) & EN 933 - 8 & 69 & - & $>55$ \\
Crushed and broken surfaces (\%) & EN 933 - 5 & 100 & 100 & 100 \\
Polished stone value (PSV) & EN 1097 - 8 & - & 0.59 & $\geq 0.56$ \\
\hline
\end{tabular}

137 The reclaimed asphalt pavement (RA) used in the investigation was from a mixed, 16 mm-sieved source. The main properties of RA used for the design of new asphalt mixtures are shown in Table 3.

\begin{tabular}{lcc}
\hline \multicolumn{1}{c}{ Property } & Standard & Results \\
\hline Density $\left(\mathrm{g} / \mathrm{cm}^{3}\right)$ & EN 1097 - 6 & 2.487 \\
Moisture content (\%) & EN 1097 - 5 & 0.83
\end{tabular}


Table 3. Main technical properties of the RA

141 The performance of AC mixtures with both binders have been analysed with the software Minitab.

142 Every mechanical test fulfilled a normal distribution and there was homogeneity of variances, so the

143 Student t-test was carried out in all cases. The confidence interval was always 95\%, so when a

144 statistical significance is below 0,05 it implies that the analysed results are significantly different.

\subsection{Experimental bitumen}

146 The stiffness and phase angle of each bitumen were evaluated using a Dynamic Shear Rheometer 147 according to EN 14770 from $30^{\circ} \mathrm{C}$ to $75^{\circ} \mathrm{C}$ and at variable frequencies. In addition, the impact of 148 adding Evotherm to the two binders was assessed. Figure 2 shows the stiffness of both bitumen with 149 Evotherm additive.
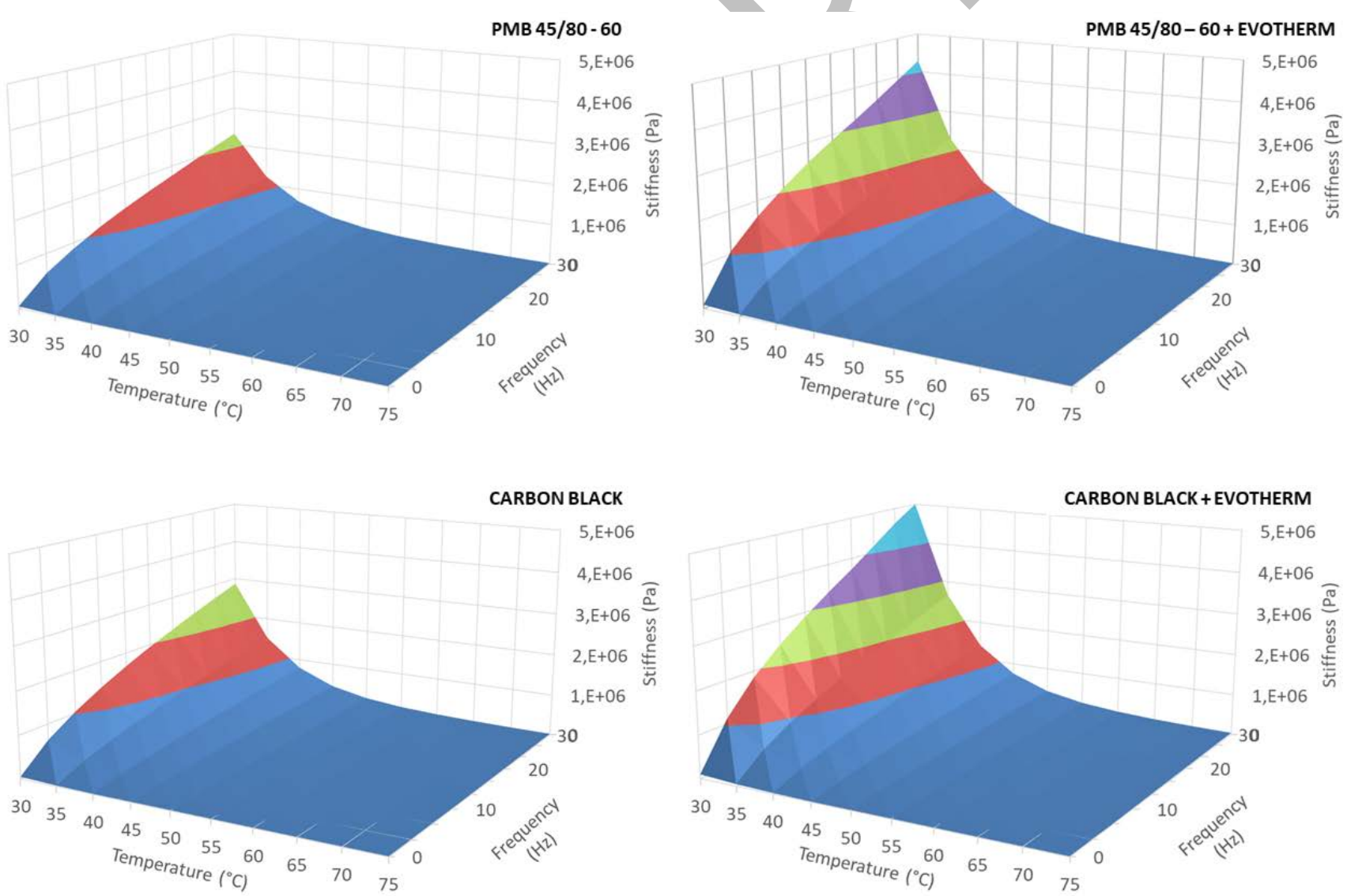

Figure 2. Stiffness of each type of binder

152 It can be seen that the binder modified with Carbon Black shows slightly higher stiffness than the 153 polymer-modified binder, but in both cases the impact of the addition of Evotherm is more noticeable, which increases the stiffness of both bitumens by practically the same proportion. 
155 The phase angle of each binder is presented in the following figure.
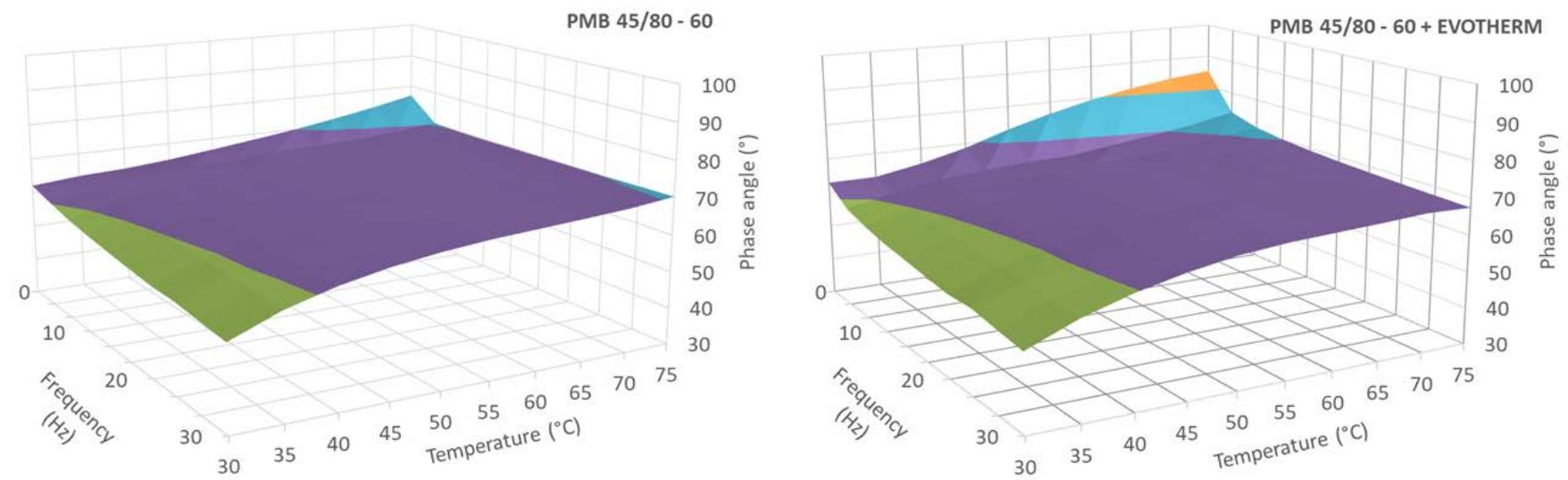

CARBON BLACK
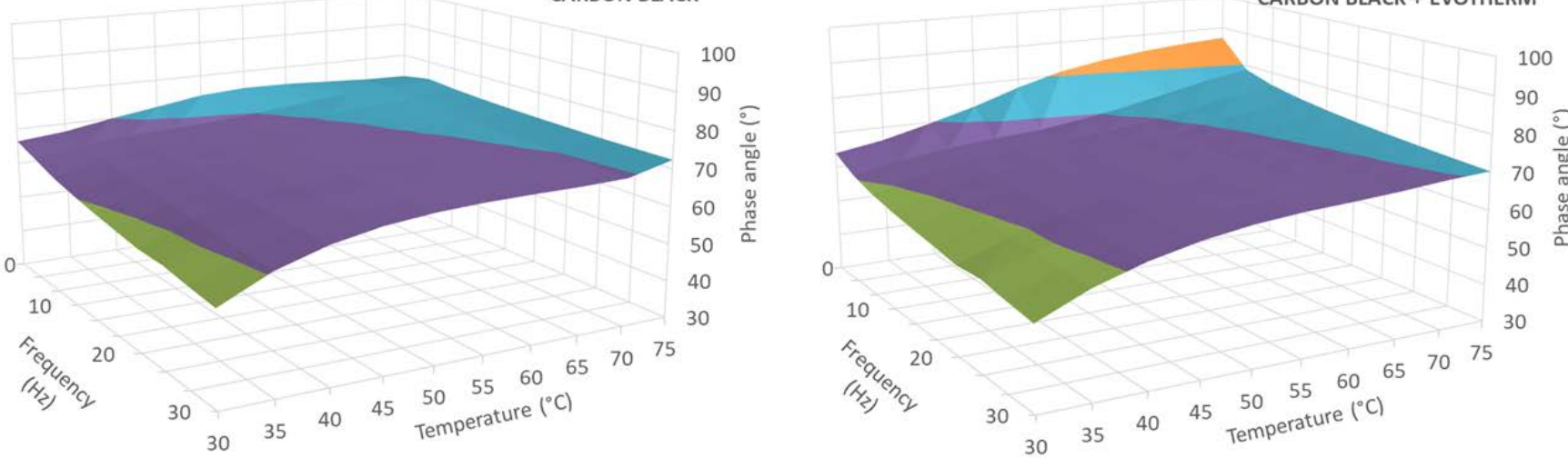

Figure 3. Phase angle of each bitumen

158 The carbon black-modified binder offers a slightly higher phase angle, which means slightly less

159 elastic behaviour. Nevertheless, when Evotherm is added values for phase angle remain practically 160 the same.

161 The Black Diagram of the two binders studied, PMB and CB, with and without Evotherm, (Figure 4)

162 shows their elastic behaviour independently of the test temperature and frequency. 


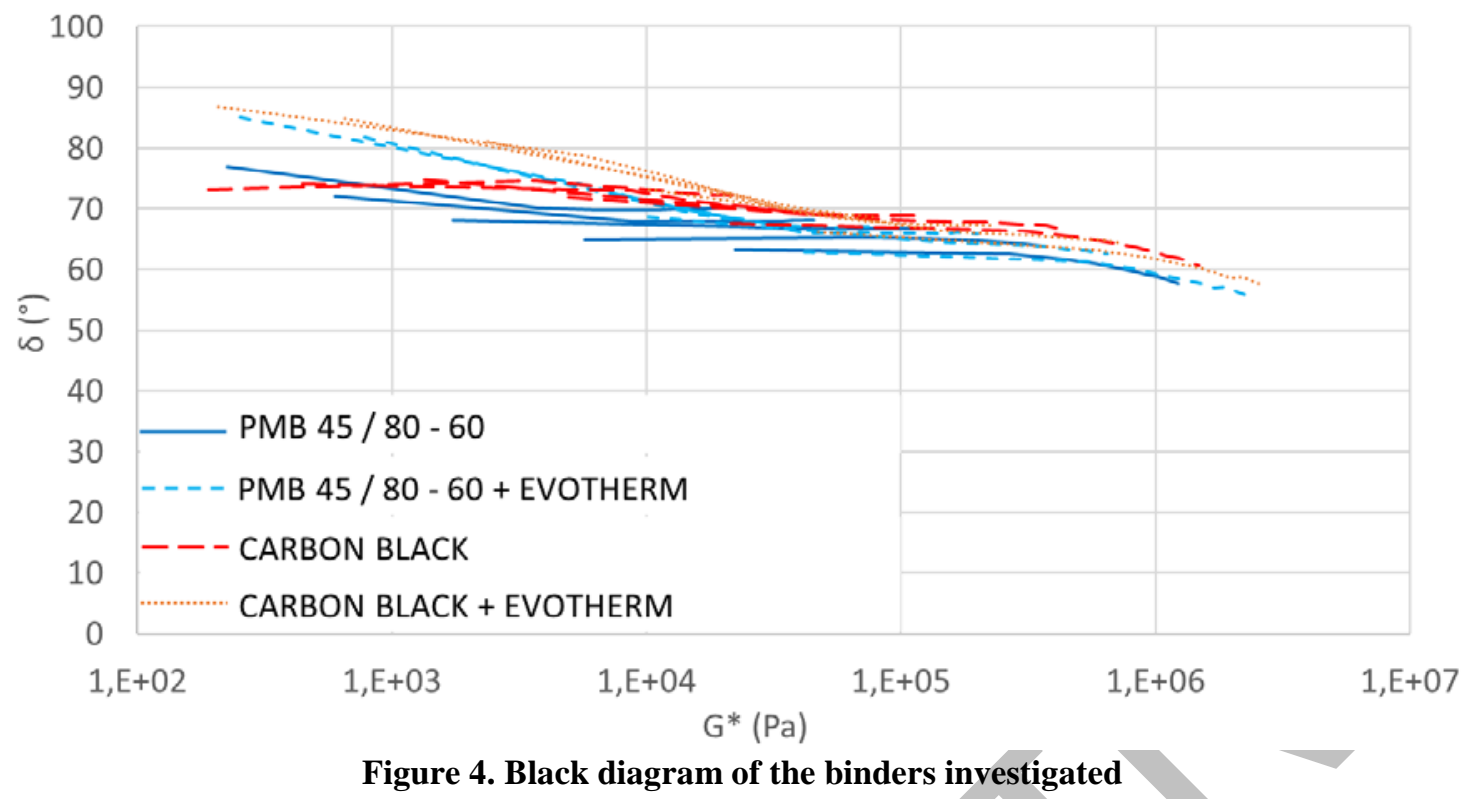

Figure 4. Black diagram of the binders investigated

165 Based on the results, the performance of the experimental binder with carbon black is very similar to 166 the commercial polymer-modified binder. In fact, the impact of Evotherm is quite similar in both 167 binders, increasing the phase angle approximately in the same proportion for the lower stiffness; this 168 is at high temperatures and low frequencies, as it can also be seen in Figure 4. In the case of higher 169 stiffness, this increase is less significant.

170 The thermal susceptibility was also analysed through the values of $\tan (\delta)$ in relation to temperature, 171 as shown in Figure 5. A more horizontal curve represents a lower susceptibility to temperature; 172 therefore, better plastic deformation performance. The frequency of $0.1 \mathrm{~Hz}$ was considered as representative because it defines the worst scenario.

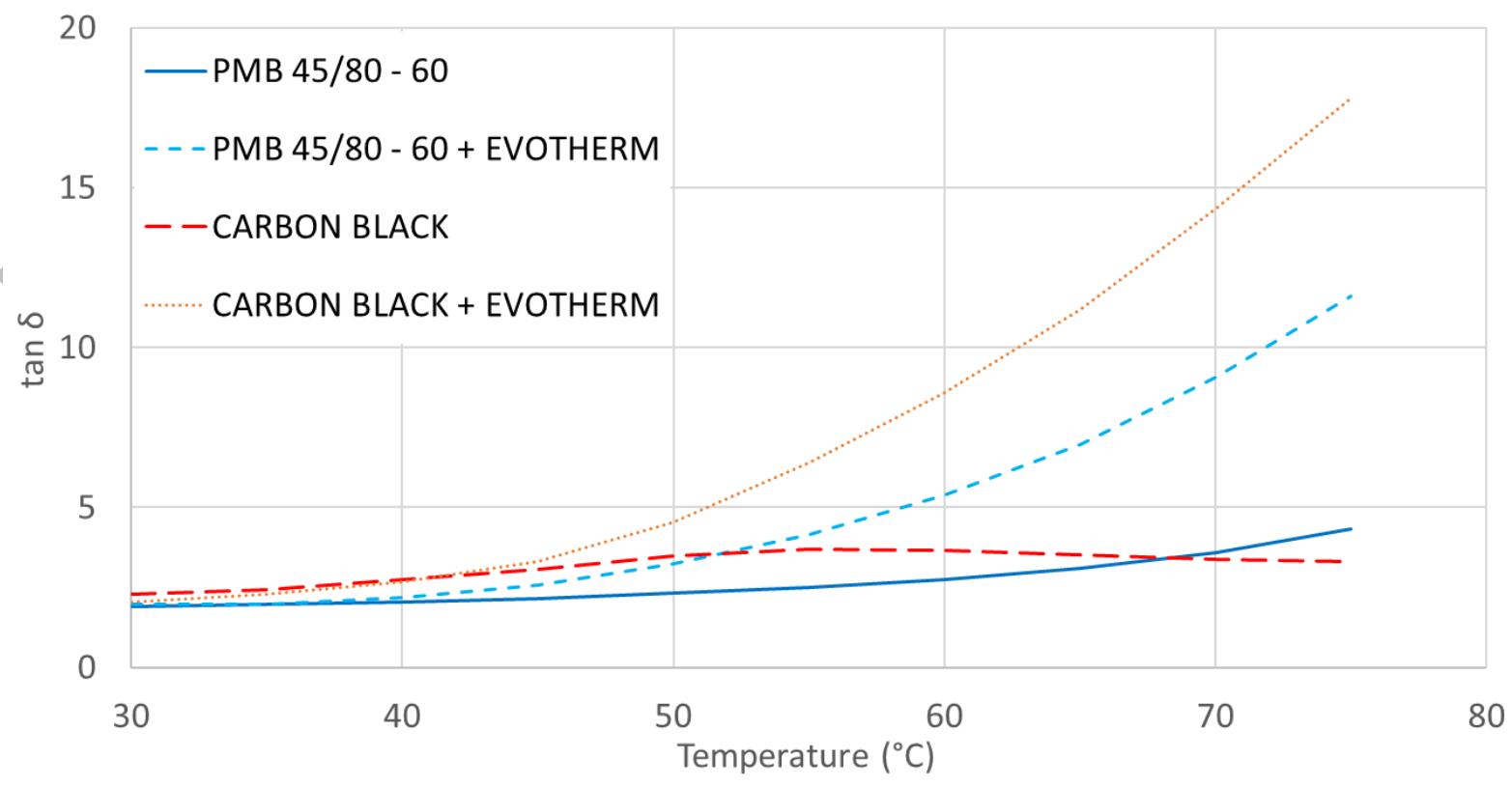


176 The thermal susceptibility is very similar in all cases up to approximately $45{ }^{\circ} \mathrm{C}$. Above this 177 temperature, the addition of Evotherm has greater impact in both modified bitumens, especially in 178 the experimental binder with Carbon Black. This can be related to the modification that Evotherm 179 produces in the bitumen to reduce its manufacturing temperature. It indicates that the thermal 180 susceptibility increases as Evotherm is added.

\subsection{Mechanical impact of the use Carbon black on the properties of the asphalt mixtures}

Slags and RA were used to partially replace virgin aggregates. Taking into account the particle size distribution of the individual components of the mixture, the grading curve of the AC16 mixture is presented in Table 4 below, which corresponds to $30 \%$ of RA, $33 \%$ of EAF slags, and $35 \%$ of natural aggregates by volume.

\begin{tabular}{ccccccccc}
\hline Sieve $(\mathrm{mm})$ & 22 & 16 & 8 & 4 & 2 & 0.5 & 0.25 & 0.063 \\
\hline \% Passing & 100.00 & 93.65 & 68.57 & 40.91 & 29.96 & 15.42 & 9.45 & 5.32 \\
\hline
\end{tabular}

Table 4. Particle size distribution of AC mixtures

Although percentages of bitumen around $4.5 \%$ are generally used, in this study the percentages examined were much lower due to the high specific weight of the slags and the percentage of residual binder included in the RA. Finally, the bitumen binder content corresponding to $5 \%$ air voids was selected as the optimum one based on the Spanish specifications. This value corresponds to $3.2 \%$ bitumen by weight. A summary of the volumetric properties for each AC mixture studied (one with the commercial polymer modified bitumen and another with the experimental bitumen with Carbon black) is shown in Table 5.

\begin{tabular}{lccc}
\hline AC 16 S & PMB & CB & $\begin{array}{c}\text { Spanish } \\
\text { standard }\end{array}$ \\
\hline Bulk density (g/cm3) & 2.639 & 2.622 & - \\
Maximum density (g/cm3) & 2.780 & 2.760 & - \\
Voids in mixture (\%) & 5.05 & 5.01 & $4-6$ \\
\hline
\end{tabular}

Table 5. Final voids characteristics of each AC mixture

The statistical analysis showed that there are not meaningful differences between the two mixtures analyzed (the p-values was 0.301), despite of the different type of bitumen used. It seems to indicate that their internal structure is similar, as they have the same granulometry and the same bitumen percentage, which was one of the objectives to analyse the CB impact respect the virgin polymers on an equal footing. 
Resistance to moisture damage was evaluated by means of the water sensitivity test in accordance with EN 12697-12 for the indirect tensile strength ratio (ITSR). Eight specimens were tested, 4 conditioned in a water bath and 4 kept in a dry environment, with the results presented in Table 6 .

\begin{tabular}{lccc}
\cline { 2 - 4 } & PMB & CB & $\begin{array}{c}\text { Spanish } \\
\text { standard* }\end{array}$ \\
\hline I.T.S. ${ }_{\text {DRY }}(\mathrm{KPa})$ & 2167.5 & 2513.2 & - \\
I.T.S. $_{\text {WET }}(\mathrm{KPa})$ & 1907.6 & 2280.6 & - \\
ITSR (\%) & 88.01 & 90.75 & $\geq 85$ \\
\hline * Most restrictive conditions \\
Table 6. Water sensitivity test results
\end{tabular}

204 The ITSR values for all the mixtures were above the specified level of $85 \%$, indicating adequate resistance to water damage. The mixture AC with $\mathrm{CB}$ showed significant higher resistance to indirect 206 tensile strength (Table 7), both in the case of dry mixtures and wet ones, reaching higher cohesion values than the mixture with PMB. Also, the damage caused by water was lower than with experimental bitumen, so it may be concluded that the CB improves this property in comparison with bitumen with commercial polymers.

\begin{tabular}{|c|c|c|}
\hline \multirow{2}{*}{ Test } & \multicolumn{2}{|c|}{ Water sensitivity } \\
\hline & Dry & Wet \\
\hline P-value & 0,013 & 0,007 \\
\hline
\end{tabular}

211 The plastic deformation of the AC mixtures was evaluated by the wheel tracking test (EN 12697 212 22) using Procedure B. Two specimens of $50 \mathrm{~mm}$ thickness were prepared by roller compactor for 213 each type of AC mixture and tested at $60^{\circ} \mathrm{C}$. The results for the mean wheel tracking slope and mean 214 rut depth compared to the limiting values in the Spanish Specifications are shown in Table 8.

\begin{tabular}{lccc} 
& PMB & CB & $\begin{array}{c}\text { Spanish } \\
\text { standard* }\end{array}$ \\
\hline Slope $\left(\mathrm{mm} / 10^{3}\right.$ cycles $)$ & 0.05 & 0.06 & $\leq 0.07$ \\
Rut $(\mathrm{mm})$ & 1.5 & 1.7 & - \\
\hline
\end{tabular}

* Most restricted conditions

216 Both AC mixtures designed met the limiting values for plastic deformation, showing good mechanical 217 performance against permanent deformation. In spite of the higher softening point and stiffness of 218 the carbon black modified binder, they display similar behaviour, which means that there is no 219 significant impact of the Carbon Black in the virgin bitumen in comparison to the use of traditional 220 polymer-modified binder (the p-values of the test was 0.394 ). This is a good result if we consider that 
221 the thermal susceptibility of the carbon black-modified binder with Evotherm is the highest as it can 222 be seen in Figure 5.

2233.3 Supplementary tests: Stiffness and resistance to fatigue

224 Dynamic tests, namely, stiffness and resistance to fatigue were carried out on samples containing the experimental binder modified with CB in order to gain further knowledge of their properties.

226 The stiffness was evaluated on prismatic beams by a 4-point bending test (EN 12697-26, Annex B). 227 The dynamic modulus at different temperatures is shown in Table 9 at a frequency of $10 \mathrm{~Hz}$. Taking 228 into consideration the temperature of $20^{\circ} \mathrm{C}$ as a reference, the stiffness is significantly higher than 229 the 6000 - $7000 \mathrm{MPa}$ considered as a reference for conventional AC mixtures ${ }^{25}$. This increase is 230 linked to the results included in Figure 2, in which an increase in the stiffness of the binder can be 231 seen in the CB and Evotherm samples.

\begin{tabular}{lccc} 
& & & \\
\hline Temperature & $5^{\circ} \mathrm{C}$ & $20^{\circ} \mathrm{C}$ & $40^{\circ} \mathrm{C}$ \\
\hline Stiffness modulus (MPa): & 22425 & 9410 & 4333 \\
Phase angle $\left(^{\circ}\right)$ & 1 & 14.7 & 23.5 \\
\hline
\end{tabular}

233 The study of the AC mixture with CB polymer-modified binder concluded with the fatigue resistance 234 test on prismatic beams (EN 12697 - 24, Annex D). In total 16 prismatic samples were examined at $23520^{\circ} \mathrm{C}$ and $10 \mathrm{~Hz}$. Table 10 presents the strain level at $10^{6}$ loading cycles $\left(\varepsilon_{6}\right)$, the fatigue law and the 236 correlation coefficient.

\begin{tabular}{ccc}
\hline $\begin{array}{c}\varepsilon_{6} \\
(\mu \mathrm{m} / \mathrm{m})\end{array}$ & fatigue law & $\mathrm{R}^{2}$ \\
\hline 136.3 & $\varepsilon(\mathrm{m} / \mathrm{m})=3.048 \cdot 10^{-3} \cdot \mathrm{N}(\text { cycles })^{-0.1962}$ & 0.98 \\
\hline & Table 10. Fatigue test results & \\
\hline
\end{tabular}

238 Results for fatigue resistance are good, especially if we consider the high stiffness of the experimental mixture. These values of stiffness and fatigue resistance indicate that the asphalt concrete mixture studied has a high load-bearing capacity with a conventional fatigue resistance.

Laboratory studies were validated by means of the construction of a trial section in which experimental AC16 mixtures with carbon black modified binder were implemented as surface course. The 100-metre long section was built in a local road in the province of Toledo, Spain. 
245 A mobile bitumen modification plant (Figure 6) placed next to the hot mix asphalt plant was used to 246 incorporate the CB and Evotherm into the binder. The resulting modified bitumen complied with the 247 requirements for a PMB 45/80-60 as in the case of the laboratory.

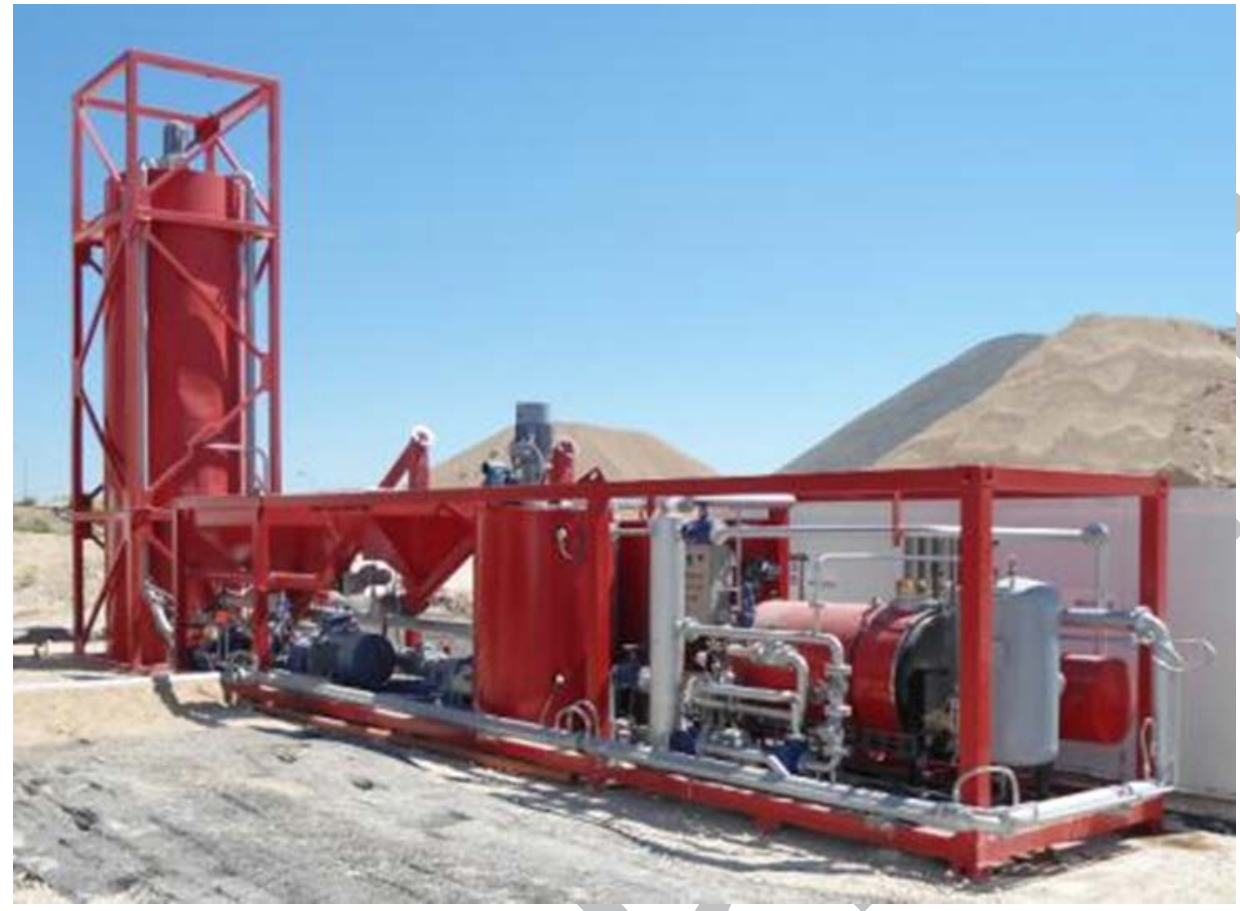

Figure 6. Modification asphalt plant

This experimental mixture was laid and compacted without difficulties. A sample of the material laid was collected from the paver prior to laying for laboratory testing. Results of these tests are shown in Table 11.

\begin{tabular}{lc}
\hline \multicolumn{1}{c}{ Property } & Real section \\
\hline Virgin binder content (\%) & 3.2 \\
Bulk density (g/cm3) & 2.613 \\
Air voids (\%) & 5.02 \\
ITS DRY (KPa) & 2755.2 \\
ITS weT (KPa) & 2573.5 \\
ITSR (\%) & 93.4 \\
WTS AIR (mm/10 3 cycles) & 0.06 \\
Stiffness (MPa) - Annex C & 11571 \\
\hline
\end{tabular}

254 The results of the mixture laid in real conditions were similar to the experimental mixture investigated at laboratory scale and fulfilled the Spanish normative. The main differences were noticed in the water sensitivity test where the real mixture achieved higher tensile strengths, also in the stiffness test because this mixture offered higher resilient modulus. These differences are not considered 
significant; they can be associated to the scaling up process, that is small variations in the mixing process, addition of CB in higher quantities, or maybe slightly higher manufacturing temperatures at real scale. Some photos that document the paving process are presented in Figure 7.

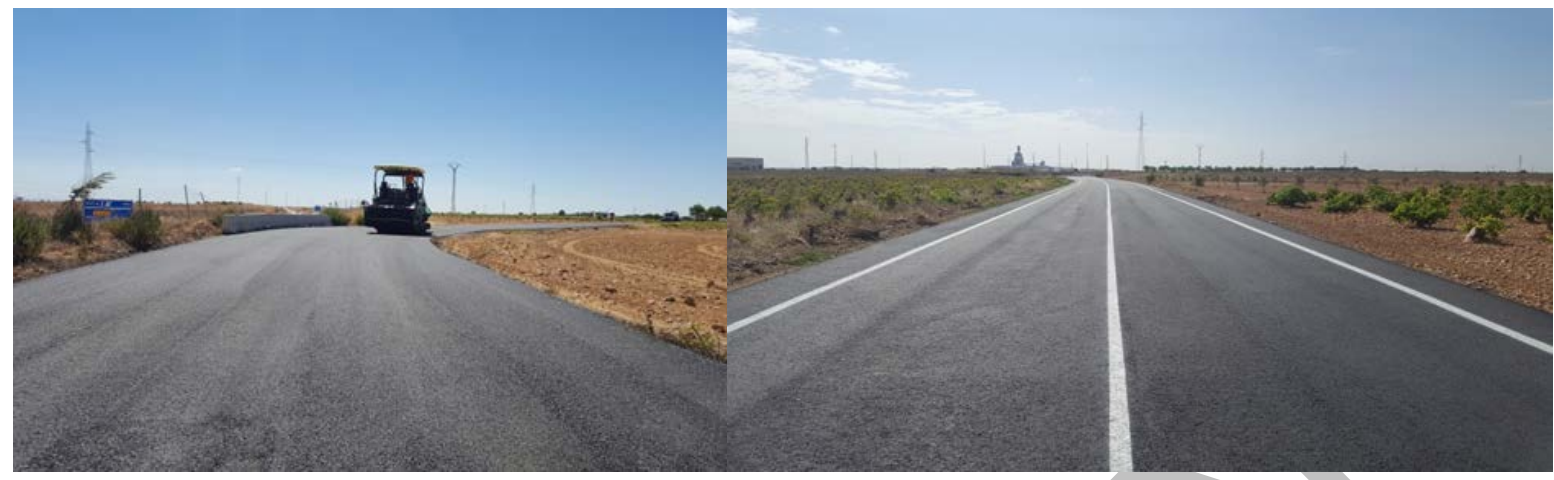

Figure 7. Experimental test section

\section{CONCLUSIONS}

An AC16 mixture was designed in order to compare the impact of an experimental modified binder with Carbon black. Furthermore, considering the current trend towards re-use and recycling of materials and by-products, these mixtures included alternative materials such as RA and EAF slags in high percentages, and Evotherm as additive to decrease its manufacturing temperature.

Based on the results of this study, the following conclusions are drawn:

- The behaviour of the experimental binder with Carbon black is quite similar to that of the commercial polymer-modified bitumen, although a slight increase in the stiffness can be observed.

- The addition of Evotherm enables the production temperature of asphalt mixtures to be decreased by $15^{\circ} \mathrm{C}$ without compromising their final properties. This enables mixtures with modified binder to be manufactured at the same temperature as mixtures with conventional 50/70 penetration grade binder.

- AC mixtures with CB polymer-modified bitumen display similar mechanical behaviour than with polymer-modified binder. There are no differences in the voids and resistance to plastic deformation; however, the mixture with $\mathrm{CB}$ increases the cohesion according to the water sensitivity test.

- The AC mixtures designed comply with the most restrictive limiting values in the Spanish specifications independently of the type of bitumen; therefore, these mixes could be laid in any Spanish road. 
- According to the dynamic tests results, AC with CB and Evotherm displays higher stiffness values than typical AC ones, while achieving a good level of fatigue resistance.

- The incorporation of steel slags and RA in percentages around $65 \%$ by volume enables a significant reduction in the use of natural aggregates without compromising the final properties.

- The AC mixtures designed were successfully implemented in a test section in Toledo, Spain. Based on the laboratory tests carried out, all the materials implemented complied with the minimum values required by Spanish standards for surface courses, which indicates that these materials can perform as satisfactorily as using traditional materials. Also, the incorporation of $\mathrm{CB}$ at real scale level was successful without any significant difficulty.

\section{ACKNOWLEDGEMENTS}

The authors would like to acknowledge that the research leading to these results has received funding from the European Union's Seventh Programme for Research, Technological Development and Demonstration under Grant Agreement nº 605404.

\section{REFERENCES}

1. Raposeiras AC, Vargas-Cerón A, Movilla-Quesada D, Castro-Fresno D. Effect of copper slag addition on mechanical behavior of asphalt mixes containing reclaimed asphalt pavement. Constr Build Mater. 2016;119:268-276.

2. Movilla-Quesada D, Raposeiras AC, Muñoz O, Castro-Fresno D. Reduction in the use of mineral aggregate by recycling cellulose ashes to decrease the aging of hot asphalt mixtures. Constr Build Mater. 2017;143:547-557.

3. Ajam H, Gómez-Meijide B, Artamendi I, Garcia A. Mechanical and healing properties of asphalt mixes reinforced with different types of waste and commercial metal particles. J Clean Prod. 2018;192:138-150.

4. Al-Mansoori T, Micaelo R, Artamendi I, Norambuena-Contreras J, Garcia A. Microcapsules for self-healing of asphalt mixture without compromising mechanical performance. Constr Build Mater. 2017;155:1091-1100.

5. Moreno-Navarro F, Sol-Sánchez M, Rubio-Gámez MC. Structural analysis of polymer modified bituminous materials in the rehabilitation of light-medium traffic volume roads. Constr Build Mater. 2017;156:621-631.

6. Centro de estudios y experimentación de obras públicas (CEDEX), ed. Ficha técnica. escorias de acería de horno de arco eléctrico. Madrid, Spain: Ministerio de Fomento. Ministerio de medio ambiente y medio rural y marino.; 2013.

7. Pasetto M, Baldo N. Experimental evaluation of high performance base course and road base asphalt concrete with electric arc furnace steel slags. J Hazard Mater. 2010;181(1-3):938-948. 
8. Behnood A, Ameri M. Experimental investigation of stone matrix asphalt mixtures containing steel slag. Sci Iranica. 2012;19(5):1214-1219.

9. Avilés Lorenzo J. Estudio de la tenacidad de los microaglomerados reciclados en caliente mediante el ensayo BTD. efecto del tipo y contenido de betún. [Departament d'Infraestructura del Transport i del Territori]. Universidad Politécnica de Cataluña; 2002.

10. Solanki P, Zaman M, Adje D, Hossain Z. Field construction and mechanistic performance of hot mix asphalt containing reclaimed asphalt pavement. International Journal of Pavement Research and Technology. 2013;6(4):403-413.

11. Shirodkar P, Mehta Y, Nolan A, Dubois E, Reger D, McCarthy L. Development of blending chart for different degrees of blending of RAP binder and virgin binder. Resour Conserv Recycling. 2013;73:156-161.

12. Gil Redondo S. Estudio de ligantes modificados con ceras mediante técnicas reológicas y calorimétricas. Carreteras. 2011;176:6-27.

13. Wu S, Zhang W, Shen S, Li X, Muhunthan B, Mohammad LN. Field-aged asphalt binder performance evaluation for evotherm warm mix asphalt: Comparisons with hot mix asphalt. Construction and Building Materials. 2017;156:574-583. doi: https://doi.org/10.1016/j.conbuildmat.2017.09.016.

14. Yang X, You Z, Hasan MRM, et al. Environmental and mechanical performance of crumb rubber modified warm mix asphalt using evotherm. Journal of Cleaner Production. 2017;159:346-358. doi: https://doi.org/10.1016/j.jclepro.2017.04.168.

15. Asphalt Institute, ed. Quantification of the effects of polymer-modified asphalt for reducing pavement distress. Engineering Report ER-215 ed. Lexington (USA): ; 2006.

16. Yildirim Y. Polymer modified asphalt binders. Constr Build Mater. 2007;21(1):66-72.

17. Moreno-Navarro F, Sol-Sánchez M, Gámiz F, Rubio-Gámez MC. Mechanical and thermal properties of graphene modified asphalt binders. Constr Build Mater. 2018;180:265-274.

18. Liu X, Wu S, Ye Q, Qiu J, Li B. Properties evaluation of asphalt-based composites with graphite and mine powders. Constr Build Mater. 2008;22(3):121-126.

19. Mirbaha B, Abdi A, Zarei M, Zarei A, Akbari nia F. Experimental determination of the optimum percentage of asphalt mixtures reinforced with nano-carbon black and polyester fiber industries. Eng Solid Mech. 2017;5(4):285-292.

20. Cong $\mathrm{P}, \mathrm{Xu} \mathrm{P}$, Chen S. Effects of carbon black on the anti aging, rheological and conductive properties of SBS/asphalt/carbon black composites. Constr Build Mater. 2014;52:306-313.

21. Ahmed TA, Lee H, Baek CM. Evaluation of laboratory and field warm mix asphalt mixtures with high contents of reclaimed asphalt pavement. Bitum Mix Pavements - Proc Int Conf Bitum Mix Pavements, ICONFBMP. 2015:623-628.

22. Ameri M, Hesami S, Goli H. Laboratory evaluation of warm mix asphalt mixtures containing electric arc furnace (EAF) steel slag. Constr Build Mater. 2013;49:611-617.

23. Lastra-González P, Calzada-Pérez MÁ, Castro-Fresno D, Vega-Zamanillo Á, Indacoechea-Vega I. Porous asphalt mixture with alternative aggregates and crumb-rubber modified binder at reduced temperature. Constr Build Mater. 2017;150:260-267.

24. Gobierno de Cantabria. Decreto 104/2006. valorización de escorias en la comunidad autónoma de cantabria. . 2006. 
360 25. Comunitat Valenciana. Direcció General d’Obres Públiques., ed. Norma de secciones de firme de 361 la comunitat valenciana. Valencia: ; 2009. Conselleria d'Infraestructures i Transport, ed. 